\title{
Developing Students' Learning and Innovation Skills Using the Virtual Smart Classroom
}

\author{
https://doi.org/10.3991/ijet.v16i04.15221 \\ Noawanit Songkram \\ Chulalongkorn University, Bangkok, Thailand \\ Learning Innovation for Thai Society Unit (LIfTS) \\ Nutthakorn Songkram $\left.{ }^{(}\right)$ \\ King Mongkut's Institute of Technology Ladkrabang, \\ Bangkok, Thailand \\ nutthakorn.so@kmitl.ac.th \\ Suparoek Chootongchai \\ Chulalongkorn University, Bangkok, Thailand \\ Thanat Samanakupt \\ King Mongkut's Institute of Technology Ladkrabang, \\ Bangkok, Thailand
}

\begin{abstract}
This study examined the development of learning and innovation skills among students in the virtual learning environment provided by the smart classroom which is comprised by three technological components containing (1) virtual 3D classroom created by Open Simulator, (2) Learning Management System (LMS) created by Moodle and (3) the add-on Moodle's plug-in, known as INNO ED TOOLs. The new system design which makes connection between the virtual 3D classroom and the LMS known as Virtual Smart Learning and Innovation System (VSLI). The VSLI was created in accordance with the principles of constructivism in order to guide and foster creative thinking among learners and enhance their skills in innovation.
\end{abstract}

Keywords — Learning and innovation skills, virtual classroom

\section{Introduction}

One of the principals aims of higher education is that learners will eventually be ready to contribute effectively to their working lives and their society upon graduation. Although it is important for learners to study content directly related to their subjects, the Association of American Colleges and Universities conducted a survey of employers in 2018 which revealed the additional needs of those employers [1]. Nine out of ten employers argued that graduates would need to be much more broadly skilled than was the case in the past, in order to be able to perform an increasingly challenging and diverse set of workplace tasks. Supporting this view, 
another study entitled "Future Work Skills 2020" [2] set out details of the skills which will be necessary.

On the basis of these requirements, those who succeed in the workplace of the future will be those who display skills in critical thinking and creative adaptability. The need for "novel and adaptive thinking" will challenge educators to find novel ways to develop the skills of the future workforce so that they are equipped to work in a world where innovation in products and services is critical. The World Intellectual Property Organization (WIPO) reported that there was an increase of $7.8 \%$ in the global number of intellectual property registrations from 2014 to 2015, emphasizing the growing importance of innovation. The leading countries were China, USA, Japan, South Korea and the nations of Europe under the European Patent Office. With a further 2.9 million patent applications in place [3] as part of a growing trend, it is clear that intellectual property is a vital global matter [4]. Many countries have accordingly set their policies to encourage innovation and soft skills in order to compete effectively with the rest of the world. Numerous universities have recognized the importance of developing their students' skills in line with the demands of the workplace, and innovation has become one of the main criteria for assessment in the university ranking systems, including the QS Stars Ratings compiled under the QS World University Rankings Methodology [5]. Innovation in the university context is partly concerned with patent applications placed with national or international patent authorities. It is therefore necessary for universities to develop policies which can encourage innovation in order to create the ideas which can bring about patent applications. Developing students is therefore vital, especially in focusing on the soft skills they will need if they are to innovate effectively for the $21^{\text {st }}$ century $[6,7]$. Under the Partnership for 21st Century Skills (P21), learning and innovation skills are described in terms of three qualities: "think creatively", "work creatively", and "implement innovations". The first of these describes the strategies required in order to generate ideas, including brainstorming, employing both incremental and radical ideas, and maximizing creativity through analyzing and refining the concepts created. The second requires that ideas are developed and communicated effectively in a cooperative environment which allows fresh ideas to flourish through collaboration and feedback. These fresh ideas would include advances upon current inventions. Furthermore, any failure should be considered as an opportunity for further learning, and it must be understood that creativity in thinking processes can take a long time. The third ideas is that new and creative ideas must be turned into physical products which can be considered to be the innovations $[8,9]$. Furthermore, there are factors to be concerned for the design of virtual classroom in order to practice social skills. According to the meta-analysis from Means, et al. [10], it was found that online learning in most studies is instructor-directed learning (effect size of $0.386, \mathrm{p}<.01$ ) while active learning and collaborative learning are less (effect size of 0.05 and 0.249 , $\mathrm{p}<.001)$. Also, type of knowledge consists of declarative knowledge at effect size of 0.180 , procedural/ Procedural and declarative knowledge at effect size of 0.239 ( $\mathrm{p}<$ .001 ) and strategic knowledge at effect size of 0.281. According to Mata analysis, the result revealed high score of effect size and significant in content based-Learning. However, effect size is low score or not significat at skills affected organization's 
performance in real business. It is implied that Design and development of tools and learning process may not have quality or do not respond to learning that emphasizes process skills.

Skills in innovation and learning have their basis in the constructivist, constructionist, and connectivist learning theories, Skills in innovation and learning have their basis in the constructivist, constructionist, and connectivist learning theories. When these skills need to be promoted, the design of systems to support learners is required. In this study, researchers developed new user-facing features which are combination of modern technologies.

In the context of this study, virtual smart classroom design is of greater importance than typical virtual classroom design because of the need for the design to incorporate both VR technology and pedagogical theories related to learning. This means that a number of relevant factors must be considered in order to develop an effective system, utilizing both technical and analytical skills [11-14]. The system comprises three subsystems: the LMS (Learning Management System), which is usually Moodle; the Moodle plug in (INNO ED TOOLs) related to innovative skills, and the virtual 3D classroom enabling the provision of scaffolding through technology. This study therefore employs constructivist learning theory to explain the learning processes involved in the creation of new knowledge, and to discuss the creation of tangible new artifacts and technology in this particular academic field.

\section{$2 \quad$ Literature Review}

The following section comprises a brief review of the literature describing the terminology involved.

\subsection{Constructivist learning theory}

Constructivist learning has been demonstrated through observation and scientific research to be a process through which learners are able to experience new ideas upon which they must subsequently reflect in order to construct their own understanding. Learners must actively process the information they receive, thus building $g$ their knowledge, rather than acting as passive recipients. For such an approach to work in the classroom setting, learners must employ active strategies, such as problem solving, in order to build new knowledge, which can then be discussed as students begin to learn how their understanding is developing. First, the teacher must know the learners' current level and understanding in order to set an activity which will allow the learners to take the next step to build on what they already know. The activity should involve real-life tasks which encourage cooperation in learning. Constructivism holds that the learners will construct knowledge through the assistance of teachers or their peers, when presented with learning materials in a particular learning environment. The role of the virtual classroom system is therefore to offer learning material and virtual situations while guiding the learners to cooperate or 
sometimes compete within a stimulating environment under the constructivist model of learning $[15,16]$.

\subsection{Constructionist learning theory}

Constructionism has its basis in constructing knowledge, but is most effective when it involves building tangible items which can subsequently be shared. The underlying concept holds that learners will learn best by making something. Experiential learning takes place, and by engaging proactively with the key concepts, the learners can build on the ideas involved. They are not merely learning by doing, however, but can reflect upon the socially shared tasks to deepen the experience. It is important to share the process as well as the finished product [17]. When the virtual smart classroom system is well-designed, it adheres to the constructionist framework which makes intervention feasible as well as challenging the traditional approaches to the implementation of such systems. In the context of learners creating new inventions or building artifacts, constructionism demands that learners employ the technology in a constructionist manner as they share the ideas with one another [1820].

\subsection{Virtual reality}

Virtual reality, or VR, is the term used to describe the simulation of reality through computer systems using a digital format. The technology integrates computer graphics with multimedia technology, sensors, artificial intelligence, and parallel real-time technology, and can be used to create a virtual classroom. The incorporation of asynchronous learning means that additional learning materials and opportunities are provided so that learners can study alone according to their own schedule. Asynchronous learning is supported by multimedia presentations and videos, in addition to message boards and feedback from submitted assignments. The advantage to learners is that the system can be accessed whenever they need in order to carry out the activities, and the teacher can be contacted whenever necessary. Synchronous learning is the name given to this kind of approach where teachers and learners meet online from different locations. All the learner needs is a device which permits internet access, and once on the network, instruction can be delivered in real time. It is possible for the instructor to follow up with learners immediately and offer real time interaction, or to schedule an online chat allowing both parties to meet in the virtual classroom by appointment. Moreover, in the collaborative learning environment, the notion of collaboration has its basis in the shared sued of the software, including whiteboards, drawing tools, mind maps, or assignment tables, through which the learners and instructors interact. For this type of study to be effective, advanced learning materials and tools are necessary along with synchronous learning approaches [21-23].

When considering the type of technology to be implemented in creating learning environments for virtual study, researchers have noted the importance of building a challenging framework. Furthermore, it must be possible for the learners to enhance 
their own learning by developing innovations. There are a number of suitable tools for this context. For instance, various communication devices can be employed in order to facilitate communication, whether synchronous or asynchronous, one-to-one, oneto-many, or many-to-many. The devices can be employed by learners in order to build upon their current knowledge or to acquire new knowledge via discussions held online. In some cases, learning systems have been devised with the capability to save chat histories through the use of one sign-in, and FAQs. Authoring tools can also be used, both in the context of the teacher and the learner. The learner context demands the use of tools including whiteboards, reflection tools, concept mappings, and blogs which allow the learners to produce and develop ideas, as well as to carry out the analysis, synthesis, and categorization of newly learned material, in addition to making comparisons while creating knowledge following lessons, or sharing experiences as a part of innovative creativity. Meanwhile, teacher context refers to the instructor developing the content for the lesson through the use of basic software. Tools allowing resources to be shared enable learners to input their own learning resources and share them with others. Through the system, learners can upload their own presentation slides or documents, with images or video content, by a simple drag and drop of the files into the correct part of the system. It is also possible to include links to other resources, such as other websites that learners wish to share. The inbuilt system of management and follow-up then helps to track the progress of the learners, recording their original access to the materials, their frequency of study, and reporting the content which has been covered. This information can be used by the instructor to monitor learner progress. To achieve this level of supervision, it is necessary to establish cooperation between the elements of IT which govern intervention policy and security. This will mean that usernames and passwords are required to ensure that only the registered learners have access to courses and materials, while the instruction materials are used for formative assessment and tests are conducted to provided summative assessments. Moreover, learners can submit self-assessment reports which can be analyzed, providing learners with online feedback to guide their progress and suggest which materials require further review, and can guide instructors by offering an overview of learner progress. Furthermore, improvements to the content can be made on the basis of the feedback received from users, ensuring that the course aims are achieved in the context of the specific learners. Navigation systems, which are typically bars linking to other pages, are useful in providing a flexible environment, giving learners additional freedoms. They can also adjust the screen so that the display meets their preferences in terms of graphics, logos, colors, and the user interface. Such settings can help learners in using the system more easily and developing a better understanding of the content. The latest advances in virtual reality technology make it possible to create a virtual 3D world as an interactive environment using tools such as 3D Builder and 3D Render. Suitable software types which can be employed, whether freely or commercially available, include OpenSimulator and Art of Illusion, since the material they produce can be seen easily on different types of devices. However, as the content is gathered and utilized by the learners, it is important that they are able to correctly reference their work and credit the sources appropriately. One way to check that this has been 
done effectively is to use plagiarism detection software, one example of which is Turnitin. The system also provides direct connections with library catalogs which can provide learners with access to digital libraries and a host of other online resources to be used in completing assignments. The tools used for evaluation and assessment can also be classified into two categories: formative assessment encompasses the use of observations, self-evaluations, and formative tests, while summative assessment is carried out through testing, portfolio submission, and the evaluation of creative presentations based on the material covered upon completion of the lessons, and following a clear rubric. Scores can be awarded on the basis of the learning standards specified at the outset, and the grades are delivered to students directly through the online system [24-28].

\subsection{Learning management system: Moodle}

Many studies have noted to academic advantages of Moodle as a learning management system [29, 30]. Readily available as an open-source program under General Public License (GPL), it could be freely downloaded. It was installed on a server offering PHP language and MySQL functioning as a Learning Management System (LMS) or Virtual Learning Environment (VLE) by the system administrator. Because Moodle has a modular structure, new courses can easily be added, making the system attractive to learners. A large number of highly effective online tools are offered to carry out a large number of different tasks, and providing different resources for learners including tests, forums, messaging, blogs, assignments, glossaries, and wikis [28]. One further advantage is the large number of users Moodle has, since these people are constantly developing new features. There are today over a thousand additional modules and plug-ins which extend the basic Moodle framework and make many further activities possible [18]. If one considers the basic functionality of Moodle, it offers a collaborative online learning environment comprising a number of adaptive components [19] which can be employed in the creation of a comprehensive virtual learning environment. Its use can assist in producing cognitive schema in students, supporting their construction of knowledge and developing higher order thinking skills. The environment can also encourage a positive approach towards collaboration with other learners through active discussion and participation in exercises designed to stimulate creative thinking and the development of new technology skills. By organizing their own interaction with the resources available in the course, learners can determine their own learning path while developing the necessary skills. Their goal must be to obtain the particular knowledge which is associated with the educational process. The system makes use of log activities, forums, and quizzes from the database, and provides feedback in the form of social network and snail graphs which make use of clustering and association rule mining algorithms [31, 32]. Furthermore, Moodle also permits the use of plug-ins which make it possible to perform additional required tasks. In fact, 1,336 plug-ins are currently available for Moodle [33]. 


\section{$3 \quad$ Research Questions}

In this research study, the technology required to support innovation and learning in the virtual smart classroom was examined. The research questions listed as follows provided the guidance for the study:

1. What is the virtual smart classroom architecture which can support learning and innovation?

2. What outcomes are achieved when learners use this approach?

\section{$4 \quad$ Research Methodology}

The research methodology involved two sections. The first was to design the virtual smart classroom architecture, while the second was to test the virtual smart classroom with the sample participant as learners.

\subsection{Virtual smart classroom architecture}

In addressing the first of the research questions, this study made use of a framework comprised three technological components related to $21^{\text {st }}$ century learning and instruction. Creativity and innovation skills can be learned online through the virtual 3D classroom, ร่วมกับ the LMS (Moodle), and the plug-in "INNO ED TOOLS". Additional plug-ins were developed for Moodle in order to further support learners in developing their learning and innovation skills. Moodle is a very well-known platform and its ability to deliver learning experiences online makes it the ideal choice for this type of situation. The virtual smart classroom itself can be further categorized into three parts as follows:

Virtual 3D classroom: When technology which permits virtual reality is brought into the classroom, it can produce a learning environment that allows learning materials to be presented through different channels, thereby enhancing the utilization of the learners. A 3D world can be formed which enables the interactions and changes in entity objects to be reflected accurately in real time for the learners, permitting their participation in exploring this virtual world through the sensual experiences of sight, hearing, and touch in a manner that can replicate the real world. In such a functional subsystem, the following details are required:

Creating an avatar is another useful cognitive method which assists learners in making the most of the virtual experience and remembering what they learned. By focusing on elements of the human memory and cognitive learning techniques, it is possible to use virtual reality learning with techniques designed specifically to improve learning outcomes. Within the field of virtual reality education, there is a high degree of cooperation among practitioners, making it possible for new ideas to be adopted readily and for materials and ideas to be generated to benefit learners. Pedagogical approaches designed on the basis of cognitive theory can be effective in helping learners to understand and recall new content, which has a much deeper and 
longer-lasting effect than mere retention over the short term for the purpose of passing examinations.

Building a whiteboard and online mind map can assist learners in producing pictures through which their ideas and opinions can be formulated and presented, either through a web browser, or a computer or tablet. This can be done within the virtual smart classroom, and hence from any physical location of the learner's choice. The website can be accessed from any location in this model. The learners can use an avatar as a means to observe their virtual world and participate in their learning. This may involve chatting in the virtual smart classroom, while teachers can monitor the chat logs in order to assess the skills and progress of the learners in this context. The learners can use the system to complete their activities and use the web board offered by the virtual smart classroom as a channel for asking questions, giving feedback and comments, and submitting their work. The program was created using OpenSimulator developed by .NET Framework. Further programming used PHP linking to SQL in order to build a seamless system allows learners' activity in the virtual smart classroom to be monitored. PHP is used to create the system which records assignments, which can later be found in the SQL database so that results can be used for calculations. The work can then be ranked using the "Hall of Fame" in the virtual smart classroom when the assets are downloaded from the server through "Media-OnPrim”.

\subsection{Learning management system: Moodle}

All of the processes involved in both instruction and learning were carried out using the LMS on the internet. The system was able to link users' computers directly to the FILE server and web server over both long and short connections. The LMS allowed the instructors to create and design the learning system through the selection of activities and learning multimedia materials which could be offered directly through the website. Further pages were also created in order to complete the design of the website. Learners were able to use the website and complete the lessons sequentially, working with each other collaboratively to create their work while communicating online. The course materials placed emphasis on discussion, reflection, and the development of innovative prototypes for new concepts. The programming required to support such materials was based on web applications coded in browser-supported language in JavaScript and HTML. This was because HTML and JavaScript need the browser in order execute the program and work well on the client-server architecture as the information is first entered by the client and subsequently stored and retrieved from the server. The role of the application server was to carry out the commanded tasks, while a dynamic database was used to store the data, and relied upon server-side processing.

\subsection{Plug-ins: "INNO ED TOOLS"}

System for student follow-up and classroom management is created through the use of the virtual 3D classroom permitting instructors to watch activity during 
learning sessions, as well as monitoring learner attendance. The system also allows the gamification of learning and presentation of resources in multimedia format. The system was also designed specifically to work effectively on mobile devices.

The overall image reflection tool is an avatar for the virtual smart classroom. It helps learners to record their ideas and reflections on each stage in a blog. Comments can be written using the plug-ins such as "Inno Smart Report (ISR)" and "Inno Smart Portfolio (ISP)". Another plug-in, "Inno Ed Tools (IET)" can be employed to evaluate these reflections through three learning dimensions, producing innovation reports delivered either as an e-Portfolio or a printed Portfolio. PHP basic language was used in developing the Inno Ed Tools plug-in in order to further develop Moodle as the LMS. The plug-in includes various tools which can serve as a set of commands capable of displaying the necessary QR codes which can act as links to the website from student blogs, whether presented in either the preview or the print mode. The command works by finding the keyword <ahref> which then links to the website referenced from the blogs. This system is presented in Figure 1 which shows the Moodle Library (serializeTCPDFRagParameter) command which serves to alter the data displayed in the QR code which appears on the screen.

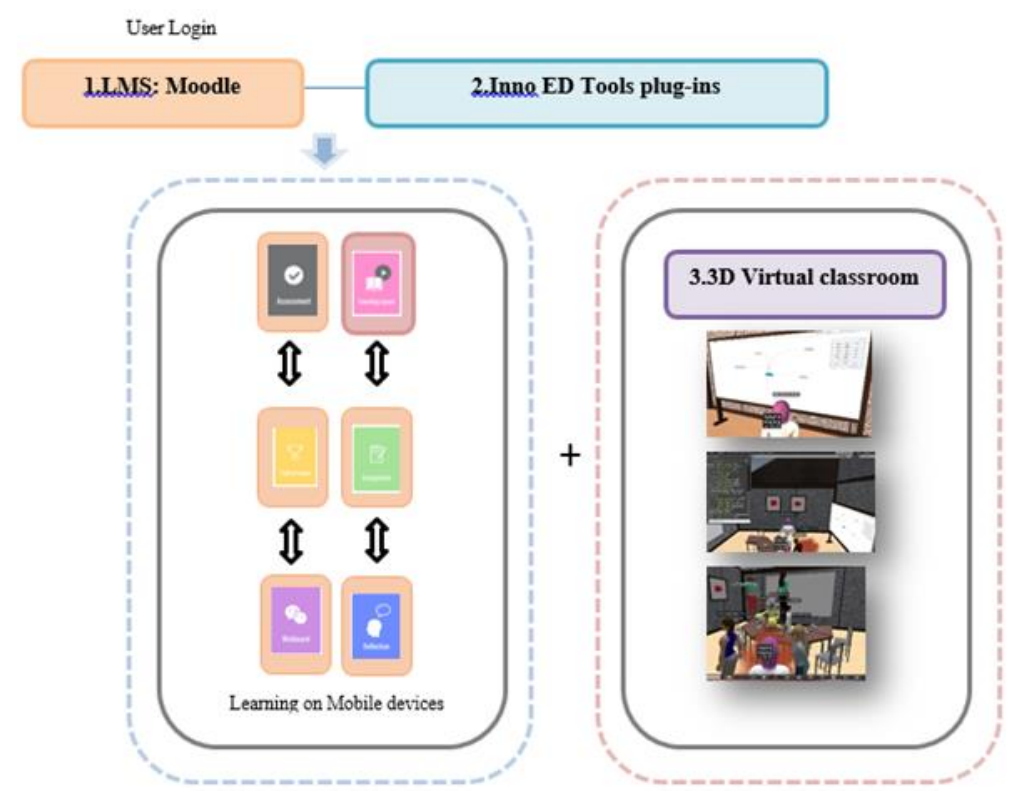

Fig. 1. Virtual smart classroom architecture

\subsection{Virtual smart classroom system testing with learners}

To address the second of the research questions, the author employed purposive sampling to obtain a sample group of students at the undergraduate level who were studying at public universities in order to test the virtual smart classroom system. A total of 83 learners were included, drawn from faculties of education, agriculture, and 
sports science, and thus encompassing the fields of social science and humanities, science and technology, and health. The first classroom had $334^{\text {th }}$ year learners who were following a course which demanded the creation of work pieces (Educational Media and Technology, Faculty of Education). The second classroom had $214^{\text {th }}$ year learners (Information Technology for Agriculture, Faculty of Agriculture). The third classroom had $294^{\text {th }}$ year learners (Sports Technology, Faculty of Sport Science).

The following steps were used to test the virtual smart classroom system. Initially, the learners underwent an orientation course explaining the virtual smart classroom system to assist them in understanding its use in developing innovation skills and learning for the era of Education 3.0. The learning activities would be carried out throughout the semester using the virtual smart classroom system. Prior to starting work using the virtual smart classroom system, each learner completed a selfassessment questionnaire gathering data on learning and innovation skills in the form of a pre-test. The three skills described earlier were assessed: creative thinking and innovation skills; critical thinking and problem-solving, and communication and collaboration. The questionnaire comprised closed questions which were answered using a five-point Likert scale. As the students participated in the study over the course of a semester, they were observed by the researchers in terms of learning and innovation skills and evaluated on the predetermined criteria. Upon completion of the study phase, the learners once again took the questionnaire, in the form of a post-test. This also measured the opinions of the learners about their experience of learning using the virtual smart classroom system. The researchers also evaluated the learners' learning and innovation skills against the same criteria as used earlier in the study.

\section{$5 \quad$ Research Results}

A sample group of 83 students was used for the testing of the virtual smart classroom system to develop learning and innovation skills. The students' skills in learning, creativity, and innovation were compared using the dependent $t$-test for a range of different time periods. 
Table 1. A comparison of the pre- and post-test scores achieved by students in the assessment of learning and innovation skills before and after the use of the virtual smart classroom system

\begin{tabular}{|c|c|c|c|c|c|c|c|c|}
\hline \multirow[t]{2}{*}{ Learning and Innovation Skills } & \multirow[t]{2}{*}{$\mathbf{k}$} & \multicolumn{2}{|c|}{ Pretest } & \multicolumn{2}{|c|}{ Posttest } & \multirow[t]{2}{*}{ MD } & \multirow[t]{2}{*}{ S.D. } & \multirow[t]{2}{*}{$\mathbf{t}$} \\
\hline & & $\mathrm{M}_{\text {pre }}$ & S.D & $\mathrm{M}_{\text {post }}$ & S.D & & & \\
\hline \multicolumn{9}{|c|}{ Three Groups of Different Disciplines ( $\mathrm{n}=83$ ) } \\
\hline $\begin{array}{l}\text { Creative Thinking and Innovation } \\
\text { Skills }\end{array}$ & 13 & 1.70 & .47 & 3.08 & .90 & 1.38 & 1.11 & $11.26^{* *}$ \\
\hline $\begin{array}{l}\text { Critical Thinking and Problem- } \\
\text { Solving Skills }\end{array}$ & 11 & 1.67 & .53 & 3.26 & .91 & 1.59 & 1.15 & $12.57 * *$ \\
\hline $\begin{array}{l}\text { Communication and Collaboration } \\
\text { Skills }\end{array}$ & 14 & 1.67 & .53 & 3.14 & .93 & 1.47 & 1.13 & $11.85^{* *}$ \\
\hline Overall & 38 & 1.73 & .47 & 3.16 & .88 & 1.43 & 1.08 & $12.07 * *$ \\
\hline
\end{tabular}

Remarks $* *$ The difference in the means is considered significant at the 0.01 level

The t-testing of the mean pre-test and post-test scores measuring learning and innovation skills among the participants before and after study in the virtual smart classroom system showed that the mean scores in all groups were higher on the posttest at the significance level of 0.01 , for both individual and overall assessments. The overall learning and innovation skill scores for the 83 participants were at a moderate level $(\mathrm{M}=3.16$, S.D. $=.88)$. The individual scores also reached the moderate level in creative thinking and innovation $(\mathrm{M}=3.08$, S.D. $=.90)$, critical thinking and problem-solving $(\mathrm{M}=3.26$, S.D. $=.91)$, and communication and collaboration $(\mathrm{M}=$ 3.14, S.D. = .93). Moreover, all of the individual skills measured for the three principal elements were found to be at the moderate level $(2.93 \leq \mathrm{M} \leq 3.337)$. When taking into account the coefficient of variation, the individual skills were all found to fall within the range of $28.43 \%$ to $39.26 \%$, with the highest ranking given to "you are able to compromise in order that the team can work to achieve the goal", and the minimum ranking given to "you are able to evaluate the situation whether it is positive or negative and arrive at appropriate solutions for the situation". For each of the individual skills, the data distribution was close to normal $(-.39 \leq \mathrm{Sk} \leq .26)$, indicating a certain level of similarity between the individual scores and the mean for the group, while individual skill kurtosis was negative and approaching zero $(-1.10 \leq$ $\mathrm{Ku} \leq-.15)$ suggesting that a majority of the skills were rated a little above the moderate level.

For the overview of the three fields of study, it was found that the pre-test and posttest mean scores were significantly higher at the 0.01 level in the case of students whose courses gave them experience in creativity and innovation. These findings can be seen in Table 1. 


\section{Discussion}

It is possible to use the virtual smart classroom system to assist learners in developing the necessary $21^{\text {st }}$ century skills in learning and innovation at the undergraduate level. The approach can be considered a form of mobile learning as well as virtual learning, and the required skills are clearly supported and promoted. All of the course components and processes have their basis and design in the theoretical approach to $21^{\text {st }}$ century learning based on research into such learning at a deeper level. There were three subsystems within the system created.

1. The virtual learning system used avatar-based VR in the form of personal icons which supported interaction with the virtual environment through graphic representation. The system could also record and store the activity of learners in the chat logs. Through the back-end system it was then possible for the instructors to see the stored data and make use of it in making evaluations. From the knowledge sharing perspective, learners were able to ask questions and post comments and reflections on their learning, all supported by the virtual 3D tools and environment. There were four virtual rooms within the virtual smart classroom system. These rooms included one hall and three classrooms. The hall included a Hall of Fame board on which the work of the learners could be displayed and voted upon. There was also an announcement board used to provide important information about the instruction process. A virtual computer was also provided to permit information searches online.

2. The mobile learning system recognized the importance of smartphones in providing lesson accessibility while maximizing convenience. A vast majority of learners have a smartphone and hence could study at any time and in any location at a relatively low cost. Furthermore, the design of the system allows it to connect the existing data with the virtual 3D tools which are available in the virtual smart classroom, while also making use of the LMS through a web application known as VSLI, or "Virtual Smart Learning and Innovation System". This application contains a number of tools. First of all is the blog which allows learners to post their thoughts and reflections during the learning process. There are online meetings available to facilitate real time cooperation. The learners' progress can be recorded as they progress through the course, and there are pre- and post-tests available so that learners can assess their own learning prior to study and upon completion of the lessons. Interactive video is also used, where questions arise during the video, and key summaries are presented along with the content to help learners focus on key points.

3. The system of plug-ins was able to augment the original functionality of the system, thereby enhancing its overall capability. This novel plug-in system is known as "Inno ED Tools" and has two principal plug-in elements as described below:

i. "Inno Smart Reports" is a plug-in which is linked to the blog for the purpose of obtaining evaluation data concerning the three skills, because 
the learners had written blog reports about their learning and the innovative skills they had developed during each of the learning phases.

ii. "Inno Smart Portfolio" is a plug-in which was developed to gather the innovative creations of the learners along with their reflections through the e-Portfolio and the printed Portfolio whether in soft or hard copy form.

4. The virtual smart classroom system is able to develop $21^{\text {st }}$ skills, especially innovation, in undergraduates, through its ability to promote transformative learning. This kind of learning extends far beyond the simple acquisition of basic knowledge since it provides more than mere content to be learned, but instead uses interaction and novel experiences to develop the underlying value of learning The narrow conceptual perspective of many learners is thus expanded via transformative learning by the new experiences they encounter. Learning requires experience, followed by critical reflection along with shared rational discourse. This study made use of transformative learning based directly upon these three requirements. Experience was delivered for learners using activities which encouraged their use of innovation skills and critical thinking in problem solving, where communication and collaboration would be vital components of the process. The activities presented make this process clear, including steps such as brainstorming, and allowing learners to follow their own instructional pathways. This can be considered the initial stage of developing one's own personal framework for learning [34-37]. Should such a framework be capable of adequately explaining an experience, the experience will become a part of the framework, and the learner will be able to use this to make the necessary personal changes which are a part of the learning process. Learners exposed to experiential learning tend to be motivated to learn in order to better understand their own perceptions and the cognitive changes they experience. The phase of critical reflection is important because the learners are obliged to select the relevant information for the discussion and sharing of knowledge with other learners in order to create innovations. In order to adjust the learning reference framework, critical reflection is essential. It also serves to link learning processes to actions, in the form of instrumental or communication learning. Instrumental learning involves the kind of learning which occurs when problems are solved and the learner observes the relevant causal relationships in doing so. Communication learning involves developing an understanding of the feelings and needs of others, and therefore demands that learners display a degree of trust and also vulnerability. There are three levels of critical reflection, encompassing content, process, and premises. Instrumental learning requires critical reflection of content and process, and one important point to consider is the question of the extent to which the acquisition of information about the content and process can be deemed reliable and accurate. In order to change one's vision or framework, critical reflection is vital, and therefore this study demanded that learners employ each of these three different forms of reflection. Meanwhile it is also important that ideas are exchanged because to do so necessitates both experience and critical thinking so that learners gain the ability to judge whether or not the knowledge they have 
obtained can be considered reliable and sufficiently accurate to be shared with others. This practice thus assists in learning and helps the analysis of the reference framework. In examination of the framework, the role of critical self-reflection is to clarify the values of all things. Meanwhile, critical discourse between learners and instructors is a form of interaction which helps to achieve personal and social transformation, both of which are mutually supportive [38, 39].

5. Education 3.0 was the concept underpinning the virtual smart classroom system to develop $21^{\text {st }}$ century learning skills for undergraduates [37, 40, 41]. The strategy is implemented in line with the vision of Thailand 4.0, which is the policy framework guiding Thailand's economic model under the notion of bringing "Stability, Prosperity, and Sustainability". In order to carry out the necessary national reforms, the direction of policy must be suitably aligned to take advantage of the opportunities of the $21^{\text {st }}$ century and to respond to the potential threats. Change must avoid imitation and must instead prioritize creativity, technology, science, research, and innovation. According to the architects of the Education 3.0 policy, this is in alignment with the goals of Thailand 4.0. Education 3.0 requires that learners collaborate in small groups using information technology to address problems with innovation thinking and interaction. It is not sufficient merely to listen to a lecture. Interactivity is required, both with instructors and other learners. Technology can facilitate this type of learning, and has therefore been integrated into the process of learning and of instruction so that students now have the opportunity to learn at any time from any location. The content can be freely obtained from open educational sources and the activities presented can focus on collaboration and the sharing of ideas in order to create new knowledge. The outcome of such a system is active learning and interaction among teachers and learners. The instructors play the role of advisors, making suggestions and providing guidance where necessary, both within the institution and in the virtual world. The $21^{\text {st }}$ century skills acquired by learners closely fit the goals of the Thailand 4.0 policy, which promotes active learning and the use of technology to develop learners' innovation skills in the hope of producing citizens who are able to propel the Thai economy to innovative successes in a wide range of fields in the coming years $[21,42,43]$.

The system overview shows that it is possible for deep learning implementation based on technology may be applicable in alternative contexts as a model of universal learning. In order to make use of such a system it is necessary first of all to evaluate the context in which it is to be employed as well as the typical limitations which may lead to shortcomings in achieving the objectives of the courses.

\section{Conclusion}

While this study achieved the initial objectives as stated from the outset, a number of limitations were encountered. One problem was that learners faced an excessive workload since they were also obliged to enrol for classes in a number of other subjects. This factor may have restricted their innovation skill development. The 
second issue was that the speed of the network was inadequate to motivate learners to participate fully in the virtual 3D learning environment.

\section{Acknowledgement}

This research is supported by Thailand Research Fund (TRF) and Ratchadapisek Somphot Fund for Postdoctoral Fellowship, Chulalongkorn University.

\section{References}

[1] H. R. Associates, "Fulfilling the American Dream: Liberal Education and the Future of Work. Selected Findings from Online Surveys of Business Executives and Hiring Managers Conducted on Behalf of the Association of American Colleges and Universities," 2018.

[2] A. Davies, D. Fidler, and M. Gorbis, "Future work skills 2020," Institute for the Future for University of Phoenix Research Institute, vol. 540, 2011.

[3] W. I. P. O. (WIPO). (2016). World Intellectual Property Indicators 2016. Available: www.wipo.int/edocs/pubdocs/en/wipo_pub_941_2016.pdf . https://doi.org/10.1787/9789 264244047-60-en

[4] W. I. P. O. (WIPO). WIPO IP Facts and Figures

[5] QS World University Rankings Available: https://www.topuniversities.com/qs-worlduniversity-rankings/methodology

[6] L. Amhag and A. Jakobsson, "Collaborative learning as a collective competence when students use the potential of meaning in asynchronous dialogues," Computers \& Education, vol. 52, pp. 656-667, 2009. https://doi.org/10.1016/j.compedu.2008.11.012

[7] J. R. Brandell, Theory \& practice in clinical social work: Sage, 2010.

[8] D. Philip, "The knowledge building paradigm: A model of learning for net generation students," Innovate: Journal of Online Education, vol. 3, 2007.

[9] P. Mishra and M. J. Koehler, "Technological pedagogical content knowledge: A framework for teacher knowledge," Teachers college record, vol. 108, p. 1017, 2006. https ://doi.org/10.1111/j.1467-9620.2006.00684.x

[10] B. Means, Y. Toyama, R. Murphy, and M. Baki, "The effectiveness of online and blended learning: A meta-analysis of the empirical literature," Teachers College Record, vol. 115, pp. 1-47, 2013.

[11] H. Ogata and Y. Yano, "Context-aware support for computer-supported ubiquitous learning," in Wireless and Mobile Technologies in Education, 2004. Proceedings. The 2nd IEEE International Workshop on, 2004, pp. 27-34. https://doi.org/10.1109/wmte.2004.12 $\underline{81330}$

[12] G.-J. Hwang, T.-C. Yang, C.-C. Tsai, and S. J. Yang, "A context-aware ubiquitous learning environment for conducting complex science experiments," Computers \& Education, vol. 53, pp. 402-413, 2009. https://doi.org/10.1016/j.compedu.2009.02.016

[13] C. Zhao and L. Wan, "A shortest learning path selection algorithm in e-learning," in Advanced Learning Technologies, 2006. Sixth International Conference on, 2006, pp. 9495. https://doi.org/10.1109/icalt.2006.1652375

[14] M. Salehi, I. N. Kamalabadi, and M. B. G. Ghoushchi, "An effective recommendation framework for personal learning environments using a learner preference tree and a GA," 
IEEE Transactions on learning technologies, vol. 6, pp. 350-363, 2013. https://doi.org/10. $\underline{1109 / \text { tlt.2013.28 }}$

[15] K. Alesandrini and L. Larson, "Teachers bridge to constructivism," The clearing house, vol. 75, pp. 118-121, 2002. https://doi.org/10.1080/00098650209599249

[16] M. Cakir, "Constructivist approaches to learning in science and their implications for science pedagogy: A literature review," International journal of environmental and science education, vol. 3, pp. 193-206, 2008.

[17] S. Papert, "Teaching children thinking," Programmed Learning and Educational Technology, vol. 9, pp. 245-255, 1972. https://doi.org/10.1080/1355800720090503

[18] P. Cobb, J. Confrey, A. DiSessa, R. Lehrer, and L. Schauble, "Design experiments in educational research," Educational researcher, vol. 32, pp. 9-13, 2003. https://doi.org/10.31 $\underline{02 / 0013189 \times 032001009}$

[19] T. Dragon, M. Mavrikis, B. M. McLaren, A. Harrer, C. Kynigos, R. Wegerif, et al., "Metafora: A web-based platform for learning to learn together in science and mathematics," IEEE Transactions on Learning Technologies, vol. 6, pp. 197-207, 2013. https://doi.org/10.1109/tlt.2013.4

[20] L. Li, Y. Zheng, H. Ogata, and Y. Yano, "Using constructionism for ubiquitous learning environment design," in E-Learn: World Conference on E-Learning in Corporate, Government, Healthcare, and Higher Education, 2003, pp. 599-602.

[21] C. de Witt, "Communication in Online Learning Communities: Digital teaching in higher education as reflected by pragmatism," zeitschrift fur padagogik, vol. 57, pp. 312-325, 2011.

[22] M. F. Fahara and A. L. Castro, "Teaching strategies to promote immediacy in online graduate courses," Open Praxis, vol. 7, pp. 363-376, 2015. https://doi.org/10.5944/open praxis.7.4.228

[23] M. K. Barbour, "Real-time virtual teaching: Lessons learned from a case study in a rural school," 2015. https://doi.org/10.24059/olj.v19i5.705

[24] I. Alvarez, T. Guasch, and A. Espasa, "University teacher roles and competencies in online learning environments: a theoretical analysis of teaching and learning practices," European Journal of Teacher Education, vol. 32, pp. 321-336, 2009. https://doi.org/10.1080/026197 $\underline{60802624104}$

[25] E. Barbera and J. A. Linder-VanBerschot, "Systemic multicultural model for online education: Tracing connections among learner inputs, instructional processes, and outcomes," Quarterly Review of Distance Education, vol. 12, p. 167, 2011.

[26] H.-F. Lin, "Measuring online learning systems success: Applying the updated DeLone and McLean model," Cyberpsychology \& behavior, vol. 10, pp. 817-820, 2007. https://doi.org/ $\underline{10.1089 / \mathrm{cpb} .2007 .9948}$

[27] M. G. Moore and G. Kearsley, Distance education: A systems view of online learning: Cengage Learning, 2011.

[28] A. van Rooyen, "Distance education accounting students' perceptions of social media integration," Procedia-Social and Behavioral Sciences, vol. 176, pp. 444-450, 2015. https:// doi.org/10.1016/j.sbspro.2015.01.495

[29] K. Kabassi, I. Dragonas, A. Ntouzevits, T. Pomonis, G. Papastathopoulos, and Y. Vozaitis, "Evaluating a learning management system for blended learning in Greek higher education," SpringerPlus, vol. 5, p. 101, 2016. https://doi.org/10.1186/s40064-016-1705-8

[30] M. M. El Tantawi, M. M. Abdelsalam, A. M. Mourady, and I. M. Elrifae, "e-Assessment in a limited-resources dental school using an open-source learning management system," Journal of dental education, vol. 79, pp. 571-583, 2015. https://doi.org/10.1002/j.0022$\underline{0337.2015 .79 .5 . t b 05917 . x}$ 
[31] X. Dong, "An overall solution of Virtual Reality classroom," in Service Operations and Logistics, and Informatics (SOLI), 2016 IEEE International Conference on, 2016, pp. 119123. https://doi.org/10.1109/soli.2016.7551672

[32] R. Ghanbarzadeh and A. H. Ghapanchi, "Applied areas of three dimensional virtual worlds in learning and teaching: a review of higher education," in Emerging tools and applications of virtual reality in education, ed: IGI Global, 2016, pp. 26-47. https://doi.org/10.4018/9 78-1-4666-9837-6.ch002

[33] (2017). Moodle Plug in Available: https://moodle.org/plugins/

[34] B. Dalgarno, S. Gregory, T. Reiners, and V. Knox, "Practising teaching using virtual classroom role plays," Australian Journal of Teacher Education, vol. 41, pp. 126-154, 2016. https://doi.org/10.14221/ajte.2016v41n1.8

[35] S. Batsakis, H. C. Mayr, V. Yakovyna, M. Nikitchenko, G. Zholtkevych, V. Kharchenko, et al., "ICT in Education, Research and Industrial Applications: Integration, Harmonization and Knowledge Transfer," 2015.

[36] R. Barmaki and C. E. Hughes, "Providing real-time feedback for student teachers in a virtual rehearsal environment," in Proceedings of the 2015 ACM on International Conference on Multimodal Interaction, 2015, pp. 531-537. https://doi.org/10.1145/28183 $\underline{46.2830604}$

[37] N. Songkram, "Online Course Design for Creativity and Innovative Skills in Virtual Cultural ASEAN Community: From Research to Empirical Practice," International Journal of Emerging Technologies in Learning (iJET), vol. 12, pp. 4-20, 2017. https://doi.org/10. 3991/ijet.v12i01.6032

[38] S. Charoenwet and A. Christensen, "The effect of Edmodo learning networ> on students' perception, self-regulated learning behaviors and learning performance," in Proceedings of The 10th International Multi-Conference on Society, Cybernetics and Informatics, 2016, pp. 297-300.

[39] P. Kapoun and J. Kapounová, "Instruction Outside the Classroom: Mobile, or Ubiquitous Learning?," in ECEL 2016-Proceedings of the 15th European Conference on e-Learning, 2016, p. 340.

[40] J. A. Paul, H. M. Baker, and J. D. Cochran, "Effect of online social networking on student academic performance," Computers in Human Behavior, vol. 28, pp. 2117-2127, 2012. https://doi.org/10.1016/j.chb.2012.06.016

[41] J. Martín-Gutiérrez, C. E. Mora, B. Añorbe-Díaz, and A. González-Marrero, "Virtual technologies trends in education," EURASIA Journal of Mathematics Science and Technology Education, vol. 13, pp. 469-486, 2017. https://doi.org/10.12973/eurasia.2017. $\underline{00626 \mathrm{a}}$

[42] (2016). Ministry of Commerce THAILAND 4.0 by MOC. Available: https://www.you tube.com/watch?v=OEfY3rQZpNo

[43] S. Das, "Virtual Classroom for Effective Learning in IT Industry," in Information Technology (ICIT), 2015 International Conference on, 2015, pp. 221-226 https://doi.org/ $\underline{10.1109 / i c i t .2015 .34}$

\section{Authors}

Noawanit Songkram, PhD., (first author) is an Associate Professor in Department of Educational Technology and Communications, Faculty of Education, Chulalongkorn University, Bangkok, Thailand. She also works at Learning Innovation 
for Thai Society (LIfTS) Research Unit, Chulalongkorn University, Bangkok, Thailand. (noawanit.s@chula.ac.th)

Nutthakorn Songkram, PhD., (corresponding author) is an Associate Professor in Department of Innovative Communication and Agricultural Development, Faculty of Agricultural Technology, King Mongkut's Institute of Technology Ladkrabang, Bangkok, Thailand. (nutthakorn.so@kmitl.ac.th)

Suparoek Chootongchai, PhD., (co-author) is a Postdoctoral Researcher in Department of Educational Technology and Communications, Faculty of Education, Chulalongkorn University, Bangkok, Thailand. (suparoek.c@ chula.ac.th).

Thanat Samanakupt, PhD., (co-author) is an Instructor in Department of Innovative Communication and Agricultural Development, Faculty of Agricultural Technology, King Mongkut's Institute of Technology Ladkrabang, Bangkok, Thailand. (samanakoopt@gmail.com).

Article submitted 2020-04-26. Resubmitted 2020-10-25. Final acceptance 2020-10-28. Final version published as submitted by the authors. 